\title{
Ciclo gonadal de hembras reproductoras de trucha arcoiris (Oncorhynchus mykiss) en la piscicultura de Río Blanco, Los Andes, Chile*
}

\author{
M. ISABEL TOLEDO D., VALIA VIVAR M. y CLAUDIA MUGA H. \\ Escuela de Ciencias del Mar \\ Universidad Católica de Valparaíso \\ Casilla 1020, Valparaíso, Chile
}

\begin{abstract}
RESUMEN. Se realizó un estudio del ciclo reproductivo gonadal anual en hembras de truchas arcoiris de la piscicultura de Río Blanco, durante el período comprendido entre su primer y segundo desove, mediante el uso de los indicadores macroscópicos: índice gonadosomático (IGS) y diámetro de los ovocitos. De acuerdo a la evolución del índice gonadosomático y diámetro de los ovocitos se sugiere que el ciclo gonadal de trucha arcoiris, dura aproximadamente un año, durante el cual los ovocitos pasan por tres etapas de desarrollo, etapa temprana, etapa de crecimiento y etapa de maduración. Se observó que un $2 \%$ de la población de hembras no alcanzó su madurez gonadal.
\end{abstract}

Palabras claves: Ciclo gonadal, ovocitos, índice gonadosomático, trucha arcoiris, Oncorhynchus mykiss.

\section{Gonadic cycle of reproductive females of rainbow trout (Oncorhynchus mykiss) in Rio Blanco, fish hatchery, Los Andes, Chile*}

\begin{abstract}
A study of the annual reproductive gonadic cycle was conducted on rainbow trout females at the Río Blanco fish hatchery, between its first and second spawning periodo. Two macroscopic indicators were used: the gonadosomatic index (IGS) and ovocytes diameter. Three developing stages are suggested for the rainbow trout according to the evolution ofthese indicators: an early stage when ovocytes are less than $0.3 \mathrm{~mm}$ in diameter, a growing stage, and a mature stage. The cycle develops in approximately one year. $1 \mathrm{t}$ was observed that about $2 \%$ of the population of females did not reached its gonadal maturity.
\end{abstract}

Key words: Gonadic cycle, oocyte, gonadosomatic index, rainbow trout, Oncorhynchus mykiss.

\section{INTRODUCCION}

El cultivo de salmónidos en Chile ha originado un nuevo impulso en el conocimiento y manejo de la reproducción de estas especies, lo que ha traído como consecuencia el desarrollo de técnicas de reproducción que posibiliten la obtención de un producto versátil y mejorado. En la actualidad, persiste la dependencia del abastecimiento de ovas provenientes del hemisferio norte; la producción nacional de ovas de

* Financiado por Proyecto FONDECYT N 0483/92. 
salmones y truchas abarca aproximadamente el 35\% de la cantidad importada (Toledo, 1992). Lo anterior ha impulsado el estudio de la fisiología reproductiva de los salmónidos, para así procurar un adecuado manejo de la reproducción de estas especies, con el fin de llegar a satisfacer la demanda nacional de ovas de óptima viabilidad y disminuir la dependencia de abastecedores de ovas extranjeras.

Es así, entonces, que el conocimiento de la biología reprodutiva de truchas de cultivo resulta ser una condición indispensable para un manejo eficiente en la reproducción artificial de esta especie (Estay et $a l ., 1990)$, ya que tanto la época de desove como la calidad de los productos sexuales puede ser alterada por las características genéticas de la población, factores ambientales y régimen alimenticio (PohlBranscheid y Holtz, 1990). Cualquier variación importante en estos parámetros afecta la eficiencia reproductiva de las hembras, alterando el desarrollo normal de los gametos, diámetro de los folículos, calidad de los huevos e índices de fecundidad (Zhang et al., 1990) y por ende la disponibilidad de un producto versátil y mejorado.

El ciclo reproductivo de hembras de truchas arcoiris ha sido investigado en el hemisferio norte por autores como Hurck y Peute (1977), Bromage (1988) y Washburn et al. (1989). Sin embargo, en Chile no se ha caracterizado completamente el ciclo reproductivo de hembras de trucha arcoiris en condiciones de cultivo, aunque existen algunos estudios realizados en poblaciones naturales o silvestres (Morrillas yValeria, 1989; Silva et al.1985; Estay et al., 1990).

En el presente trabajo, se efectuó un estudio del ciclo reproductivo de hembras de trucha arcoiris en la Piscicu1 tura de Río Blanco, en el período compren dido entre el primer y segundo desove, 1992 y 1993 respectivamente. Se cuantificó el índice gonadosomático y el diámetro de los ovocitos, para así contar con una base referencial, para futuras investigaciones con reproductores de esta especie, que tengan como objetivo la producción de ovas viables para sustentar la demanda nacional.

\section{MATERIALES y METODOS}

En la Piscicultura de Río Blanco, entre julio 1992 y julio 1993, se mantuvieron en estanques circulares 50 hembras reproductoras de trucha arcoiris de dos años de edad y de primer desove, con un peso promedio inicial de $549,6 \pm 85 \mathrm{~g}$ y una longitud promedio de 35,6 $\pm 1,6 \mathrm{~cm}$, alimentándose dos veces al día, según la tabla de alimentación propuesta por Leitritz y Lewis (1980). El flujo de agua fue de 71/ seg y la temperatura del agua fluctuó entre los $5^{\circ}$ y $12^{\circ} \mathrm{C}$.

Mensualmente se muestreó el 6\% de los individuos, a los que se les registró peso y longitud. Los peces fueron sacrificados y se les extrajo los ovarios, los que fueron pesados y medidos para calcular la variación del índice gonadosomático a partir de la fórmula siguiente:

$$
\text { IGS }=\frac{\text { Peso de la gónada }(\mathrm{g})}{\text { Peso total del ejemplar }(\mathrm{g})} * 100
$$

De cada ovario se tomaron submuestras y se midió el diámetro de los ovocitos según la metodología propuesta por Olsen y Rulifson (1992). Los datos obtenidos fueron comparados con los criterios de maduración usados por Tyler et al. (1991), y Bromage y Cumaranatunga (1988).

Para determinar el grado de madurez de las hembras se tomó como base los datos históricos de la Piscicultura (dato no publicado) y a partir de mayo de 1993 se examinó semanalmente al grupo de peces dos meses previos al desove. El desove artificial se indujo mediante masaje abdominal de los individuos, los que previamente fueron anestesiados con MS222 (tricaína metasulfato) en concentración de $50 \mathrm{mg} / \mathrm{l}$.

\section{RESULTADOS Y DISCUSION}

La duración total del ciclo gonadal para la trucha arco iris es de aproximadamente un año, período que puede variar de acuerdo a las razas, condiciones climáticas y alimentación (Tyler et al., 1991). El índice gonadosomático obtenido en este estudio, al igual que los encontrados por autores como Silva et al. (1985) y Estay et al. (1990) en nuestro país y por Washburn et al. (1990); Bourlier y Billard (1984) y Billard (1992) en el hemisferio norte, sigue un patrón de comportamiento en que se observa bajos valores en los meses posteriores al desove, aumenta lentamente hasta el quinto mes post -desove, momento en que alcanzan un brusco incremento, para llegar a un máximo en la ovulación.

En la curva del índice gonadosomático (1GS) ob- 
tenida de los ejemplares seleccionados (Fig. 1), se puede observar que previo al primer desove, julioagosto 1992, el índice gonadosomático alcanza un valor máximo de $11 \%$, después del desove, este valor disminuye hasta $0,9 \%$, manteniéndose bajo el $4 \%$, desde septiembre a noviembre. Entre diciembre y mayo ocurre un aumento de este índice desde un 4,5 a un $12 \%$. De mayo hasta junio se observa un aumento brusco del índice gonadosomático, de un $12 \%$ hasta un $17 \%$, correspondiendo este último al máximo valor, que ocurre previo al segundo desove. Luego del desove, el índice desciende a valores cercanos al $1 \%$.

Paralelamente a la evolución del IGS, los ovocitos experimentan un desarrollo continuo conducente a su maduración (Fig. 1), esto se traduce en una serie de cambios a nivel hormonal y celular (Billard, 1992), los cuales se ven reflejados en el aumento de tamafio, que se utilizó para definir estados de maduración ovocitario. Comparando el valor promedio de los diámetros registrados en esta experiencia y los diámetros registrados por Bromage y Cumaranatunga (1988), en las distintas etapas de madurez gonadal, además de la variación del índice gonadosomático, es posible sugerir que los ovocitos de trucha arcoiris pasan por tres etapas de desarrollo, que se pueden clasificar como: etapa temprana de la ovogenésis, etapa de crecimiento y etapa de maduración.

De acuerdo a Tyler et al. (1991), la etapa temprana de ovogénesis se caracteriza por la presencia de un gran número de ovocitos de tamafio inferior a los 0,4 $\mathrm{mm}$. Mientras que Bromage y Cumaranatunga (1988) establecen para esta etapa, que el límite del diámetro de los ovocitos varía entre 0,3 y 0,4 mm. Basándose en estos criterios, se establece para esta experiencia un diámetro máximo de $0,3 \mathrm{~mm}$. Esta primera etapa, temprana de la ovogénesis, ocurre en los meses posteriores al desove, agosto-noviembre (Tabla 1).

La segunda etapa o etapa de crecimiento, se relaciona con la fase de vitelogénesis, la cual presenta dos estadios separados por un brusco aumento en el tamafio de los ovocitos. El primero corresponde a la vitelogénesis exógena, proceso en el cual, según Billard (1992), los ovocitos presentan tamaños que fluctúan entre 0,25 y $0,6 \mathrm{~mm}$, seguido por una fase de



Figura 1. Evolución del índice gonadosomático y diámetro de ovocitos de truchas arco iris (Oncorhynchus mykiss) en la piscicultura de Río Blanco (1992-1993). 
Tabla 1. Porcentaje de ovocitos en las diferentes etapas de desarrollo ovocitario en la piscicultura de Río Blanco

\begin{tabular}{cccc}
\hline $\begin{array}{c}\text { Diámetro } \\
\text { ovocitos } \\
\mathrm{mm}\left({ }^{*}\right)\end{array}$ & $\begin{array}{c}\text { Temprana } \\
\text { Ago-Nov } \\
\%\end{array}$ & $\begin{array}{c}\text { Crecimiento } \\
\text { Dic-Abr } \\
\%\end{array}$ & $\begin{array}{c}\text { Maduración } \\
\text { May-Jul } \\
\%\end{array}$ \\
\hline$<0,3$ & 95 & 15 & 5 \\
$0,30-2,50$ & 5 & 77 & 20 \\
$>2,50$ & 0 & 8 & 75 \\
\hline
\end{tabular}

* Rangos modificados a partir de Tyler et al. (1991) y Bromage y Cumaranatunga (1988).

vitelogénesis endógena, en que los ovocitos experimentan un gran desarrollo citoplasmático, que se visualiza a través del aumento progresivo de su diámetro, que va de 1 a 2,5 rnm (Tyler et al., 1991). Para esta investigación se puede decir que la segunda etapa, de crecimiento, transcurre entre diciembre y abril, puesto que se pudo observar que gran parte de los ovocitos presentaron tamaños que fluctuaron entre 0,3 y $2,5 \mathrm{~mm}$. Sin embargo, durante diciembre y enero, la mayoría de los ovocitos, presentó un diámetro que osciló entre los 0,3 y 0,6 mm, para experimentar un aumento progresivo de su diamétro, de 1,0 a 2,5 mm de febrero a abril.

El período de maduración, según Bromage y Cumaranatunga (1988), se caracteriza por el predominio de ovocitos de tamaño superior a $3 \mathrm{~mm}$. De acuerdo a los resultados de esta investigación, entre mayo y junio un $75 \%$ de los ovocitos midió más de $3 \mathrm{~mm}$, alcanzando un diámetro de $5+/-0,5 \mathrm{~mm}$ en el momento de la ovulación; este periodo se podria denominar como etapa de maduración.

El 2\% de las truchas estudiadas no alcanzó a completar su ciclo reproductivo, presentando ovarios inmaduros, con un predominio de ovocitos de 1,0 a 1,5 mm de diámetro. En los estudios del ciclo reproductivo gonadal efectuados en esta misma es pecie por Estay et al. (1990) se encontró que en la población estudiada existía la presencia de hembras con ovarios en reposo y con ovocitos previtelogénicos. Estos autores postulan que es común encontrar, dentro de una población, un grupo que no desova regularmente. No obstante, no se cita el por- centaje de la población que no alcanzó la madurez gonadal.

En esta investigación, se determinó macroscópicamente el ciclo reproductivo anual de truchas arcoiris cultivadas en la Piscicultura de Río Blanco y se concluye que en términos generales, coincide con lo observado en otras regiones del país. Sin embargo, es necesario complementar este estudio macroscópico con un estudio histológico, que permita determinar con mayor precisión el estado de madurez de los ovocitos.

\section{REFERENCIAS BIBLIOGRAFICAS}

BILLARD, R 1992. Reproduction in rainbow trout: sex differentiation, dynamics of gametogenesis, biology and preservation of gametes. Aquacuhure, 100:263-298.

BOURLIER, A. and R. BILLARD. 1984. Delayed gametogenesis and spawning in rainbow trout (Salmo gairdneri) kept under permanent light during the first and second reproductive cycles. Aquacuhure, 43: 259-68.

BROMAGE, N.R 1988. Egg production in the rainbow trout. In: R.J. Roberts and J.F. Muir. (Eds.) Recent Advances in Aquaculture, Vol 3. Croom Helm., London, pp. 63-138.

BROMAGE, N.R. and R. CUMARANATUNGA. 1988. Egg production in the rainbow trou1. Rec. Adv. in Aquaculture, 3: 63-138.

ESTAY, F., N. DIAZ y J. MELLA. 1990. Ciclo reproductivo gonadal de una población de trucha arco iris, (Oncorhynchus mykiss), de la zona central de Chile. Medio Ambiente, 11(1): 15-23.

HURK, R. van den and J. PEUTE. 1979. Cyclic changes in the ovary of the rainbow trout (Salmo gairdneri), with special- reference to sites of steroidogenesis. Cell Tissue Res., 199: 289-306.

LEITRITZ, E. and R. LEWIS. 1980. Trout and salmon culture, (Hatchery Methods), Cal. Fish Bull., 164, 197 pp.

MORILLAS, J. y H. VALERIA. 1984. Microscopía cuantitativa y madurez sexual de trucha arcoiris (Salmo gairdneri R.). Bol. Soc. Biol. Concepción, 55: 119-124. 
OLSEN, E.J. and R.A. RULIFSON. 1992. Maturationand fecundity of Roanoke RiverAlbermarle Sound Striped Bass. Trans. Amer. Fish. Soc., 121: 524-537.

POHL-BRANSCHEID, M. and W. HOLTZ. 1990. Control of spawning activity in male and female rainbow trout (Oncorhynchus mykiss) by repeated foreshortened seasonal light cycles. Aquaculture, 86: 93-104.

SILVA, A., L. FRANCO y N. ITURRA. 1985. Antecedentes sobre reproducción y alimentación de la trucha arcoiris (Salmo gairdneri) del embalse Conchi, Antofagasta, Chile. Biol. Pesq., 14: 3239.

TOLEDO, M.I. 1992. Manejo alimentario de reproductores. Aquanoticias Internacional, 13: 2023.

Recibido el 8 de marzo de 1994. Aceptado el 30 de agosto de 1994.
TYLER, C.R., J.P. SUMPTER and P.M. CAMPBELL. 1991. Uptake of vitellogenin into oocytes during early vitellogenic development in the rainbow trout (Oncorhychus mykiss W.). J. Fish Biol., 38: 681-689.

WASHBURN, B.S., D.J. FRYE, S.S.O. HUNG, S.I. DOROSHOV. and F.S. CONTE. 1990. Dietary effects on tissue composition, oogenesis and the reproductive performance of female rainbow trout (Oncorhynchus mykiss). Aquaculture, 90: 179195.

ZHANG, H., G.A. GALL and S.S. HUNG. 1990. Effect of sire diet and week of spawning on volume of eggs retained by artificially spawned rainbow trout. Aquaculture, 87: 23- 33. 